\title{
A Male Case of Renal Amyloidosis
}

\author{
Ziryab Imad Taha ${ }^{1,2^{*}} \mathbb{0}$, Mohammed Elmujtba Adam Essa ${ }^{2,3^{*}}{ }^{\infty}$, Asaad Tageldein Idris Abdelhalim ${ }^{4}$, \\ Mohey Aldein Ahmed Elamin Elnour ${ }^{5}$, Allaa Ahmed Osman Eltayeb ${ }^{6}$ \\ Shaza Adel Awad Mohammed Elwakeel ${ }^{7}$ and Abdelkareem Abdallah Ahmed ${ }^{2,8,9,10^{*}}$ [0
}

${ }^{1}$ Department of Internal Medicine, Faculty of Medicine, University of Bahri, Khartoum, Sudan; ${ }^{2}$ Department of Clinical Medicine, Medical and Cancer Research Institute (MCRI), Nyala, Sudan; ${ }^{3}$ Faculty of Medicine, Alfashir University, Al Fashir, Sudan; ${ }^{4}$ Department of Clinical Immunology, Sudan Medical Specialization Counsel, Khartoum, Sudan; ${ }^{5}$ Faculty of Medicine, Omdurman Islamic University, Khartoum, Sudan; ${ }^{6}$ Faculty of Medicine, Ahfad University for Women, Khartoum, Sudan; ${ }^{7}$ Faculty of Medicine and Health Science, University of Gadarif, Gadarif, Sudan; ${ }^{8}$ Department of Physiology and Biochemistry, Faculty of Veterinary Science, University of Nyala, Nyala, Sudan; ${ }^{9}$ Biomedical Research Institute, Darfur University College, Nyala, Sudan; ${ }^{10}$ Institute of Molecular Biology, University of Nyala, Nyala, Sudan

\begin{abstract}
Amyloidosis is a group of rare, serious disorders caused by deposition of amyloid protein in tissues, such as the kidney, heart and brain. However, there is no case reported from Sudan. Here, we report one male case of renal amyloidosis, possibly secondary to abdominal tuberculosis (Tb). A male, 30 years of age, complained of systemic body swelling, shortness of breath, and decreased urine output with abnormal color for 2 months. He had been diagnosed with abdominal Tb 10 years prior, for which he received systemic anti-Tb treatment. Clinical examination exhibited anasarca, particularly in the abdomen. Abdominal ultrasound indicated massive ascites, and echocardiography indicated the ejection fraction reduced to $60 \%$. Renal biopsy revealed renal amyloidosis. The patient was treated with ceftriaxone, furosemide, prednisolone, pantoprazole, spironolactone, calcium and mycophenolate mofetil, and his condition improved. The patient was discharged 2 weeks after treatments. Hence, this is the first case of renal amyloidosis, possibly secondary to abdominal Tb, in Sudan. This case report should serve as an alert to physicians working in high-prevalence Tb regions.
\end{abstract}

\section{Introduction}

Amyloidosis (AL) is a group of rare diseases and pathologically is characterized by abnormal deposition of fibril-like insoluble amyloid protein in body organs, causing organ damage that leads to death. There are approximately 60 heterogeneous amyloidogenic proteins, and 27 of these are associated with known human diseases, affecting the liver, kidney, peripheral nervous system, and heart. ${ }^{1}$ If the bone marrow is involved, the case may be linked

Keywords: Secondary amyloidosis; Anasarca; Renal biopsy; Tuberculosis.

Abbreviations: AL, amyloidosis; Tb, tuberculosis

Received: September 28, 2020; Revised: October 29, 2020; Accepted: November 10, 2020

*Correspondence to: Ziryab Imad Taha, Department of Internal Medicine, Faculty of Medicine, University of Bahri, Khartoum, Sudan. ORCID: https://orcid.org/0000 0001-9104-1737; Mohammed Elmujtba Adam Essa, Department of Clinical Medicine, Medical and Cancer Research Institute, Nyala, Sudan. ORCID: https://orcid. org/0000-0002-1050-2771, Tel: 00249907009389,E-mail: Awadali818@yahoo.com; Abdelkareem Abdallah Ahmed, Department of Physiology and Biochemistry, Faculty of Veterinary Science, University of Nyala, Nyala, P.O. Box: 155 Nyala, Sudan. ORCID: https://orcid.org/0000-0003-1524-0392, E-mail: kareemo151@gamil.com How to cite this article: Taha ZI, Adam Essa ME, Idris Abdelhalim AT, Elamin Elnour MAA, Osman Eltayeb AA, Mohammed Elwakeel SAA, Abdallah Ahmed A. A Male Case of Renal Amyloidosis. J Explor Res Pharmacol 2020;000(000):000-000. doi: $10.14218 /$ JERP.2020.00031. with multiple myeloma. ${ }^{2}$ Without optimal treatment, AL has a very high death rate, of approximately $75 \%$ within a 2 -year period after diagnosis. ${ }^{3}$ AL can be diagnosed pathologically and classified by immunohistochemistry and mass spectrometry. ${ }^{4}$ However, there has been no case reported from Sudan, Here, we report a male case of renal AL, possibly associated with abdominal tuberculosis (Tb). This case report should serve as an alert of clinical attention to physicians in the high-prevalence $\mathrm{Tb}$ regions.

\section{Case report}

A male patient, 30 years-old, was brought to Haj-Elsafi General Hospital, Khartoum, Sudan, on March 2019. He complained of systemic body swelling that had lasted for 2 months. He reported having begun to develop bilateral lower limb swelling, which was more severe while standing and walking and which also started 2 months prior (Fig. 1). One month prior to hospital presentation, he noticed scrotal, abdominal and facial swelling (Fig. 1). He had shortness of breath with exertion and when lying down. He reported that his urine output was reduced and frothy in the morning, but without obvious burning or pain sensations and without symptoms related to urinary tract obstruction. He reported no fever, fatigue, no weight loss, appetite change, vomiting, abdominal pain, change 


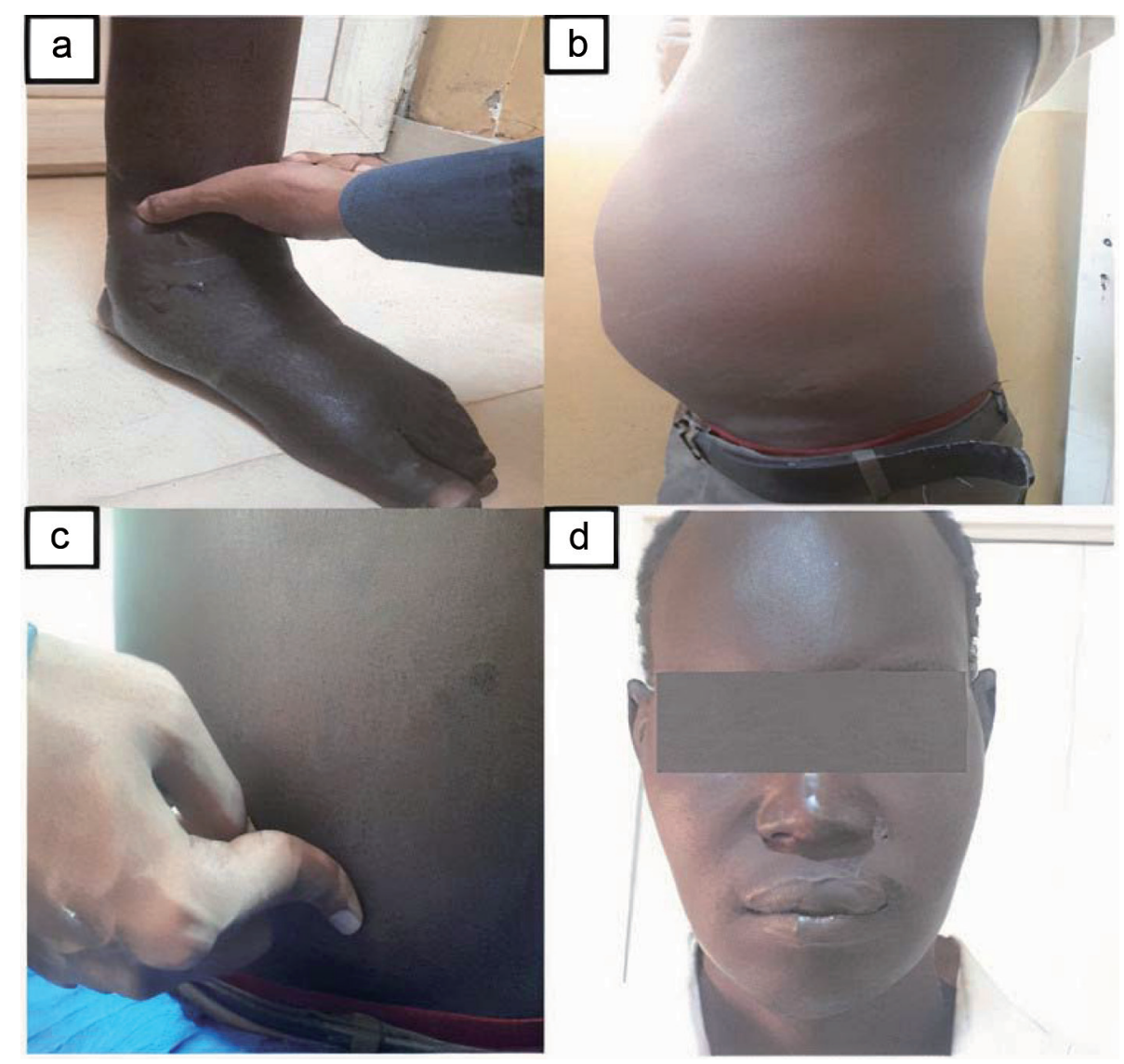

Fig. 1. Patient display of systemic edema. (a) Lower limb edema. (b) Ascites. (c) Sacral edema. (d) Facial swelling.

in bowel habit, headache, memory functional change, nor effects of muscular movement.

The patient reported smoking tobacco moderately and drinking alcohol occasionally. He was allergic to penicillin. He had no diabetes, hypertension nor chronic cardiovascular disease. He had been diagnosed with abdominal $\mathrm{Tb} 10$ years prior and received regular anti- $\mathrm{Tb}$ treatments. His family members were generally healthy, with no specific reports of illness or conditions.

Physical examination found that, in general, he was weak but not pale or jaundiced. Abdominal examination detected a distended abdomen, with full flanks, positive shifting dullness, fluid thrill and pitting edema in the lower limbs up to the knee. Abdominal ultrasound indicated massive ascites and mild liver enlargement with low homogeneous texture. Echocardiography revealed ejection fraction of $60 \%$ and sinus tachycardia without abnormal valves, general work up done (Table 1), He also underwent a renal biopsy. His renal tissue sections were stained with hematoxylin-eosin, periodic acid Schiff (PAS), Mucin Stain (MS) and sliver and represented $70 \%$ renal cortex and $40 \%$ medulla, muscles, and adipose tissues. Pathologically, his renal tissues displayed a wide eosinophilic mesangial increase extended to the loops of the glomerular capillary, a hallmark of renal amyloidosis (Fig. 2).

Given his past history of abdominal $\mathrm{Tb}$, unexplained systemic body edema, particularly for massive ascites, and typical pathological characteristics of his renal tissue sections, he was diagnosed with AL, possibly secondary to previous abdominal $\mathrm{Tb}$. The patient was treated with $1 \mathrm{~g}$ ceftriaxone b.i.d for 5 days, $20 \mathrm{mg}$ injectable furosemide b.i.d for 3 days, $30 \mathrm{mg}$ prednisolone daily tapered by $5 \mathrm{mg}$ weekly, $20 \mathrm{mg}$ pantoprazole daily, $25 \mathrm{mg}$ spironolactone daily, $500 \mathrm{mg}$ calcium daily, and $500 \mathrm{mg}$ mycophenolate mofetil b.i.d. Two weeks later, his overall condition had improved and he was discharged.

\section{Discussion}

Renal AL is a rare disease and hard to diagnose because of its early unspecific symptoms, particularly before onset of organ failure. ${ }^{5}$ AL can display systemic or localized symptoms, such as fatigue and weight loss, which usually occur after an organ has become severely damaged. Our patient complained of symptoms similar to nephrotic syndrome lasting for 2 months. Some multiple myeloma patients may present with similar symptoms, but for our patient this was excluded by the absent evidence of malignancy. ${ }^{2}$ Renal AL patients usually die of both renal and heart failure. ${ }^{6}$ Fortunately, our patient achieved improvement in clinical symptoms after treatments that lasted for 2 weeks. Hence, early diagnosis and treatment of AL are crucial for saving an AL patient's life.

Secondary AL can occur during the progression of many infectious and chronic inflammatory diseases, ${ }^{7}$ such as familial Mediterranean fever in Turkish people, ${ }^{8}$ juvenile idiopathic arthritis, rheumatoid arthritis, inflammatory bowel diseases and ankylosing spondylitis in western countries. ${ }^{9}$ In developing countries, Tb and other infectious diseases remain the most common predisposing factors for secondary AL, with a declining trend. ${ }^{10}$ Our patient had a history of abdominal $\mathrm{Tb}$ and received anti-TB therapies. When 
Table 1. Lab test results for the patient

\begin{tabular}{|c|c|c|}
\hline Parameter & Result & Reference \\
\hline White blood cell count & 8,000 cells $/ \mathrm{mcl}$ & $4-11 \times 10^{9} / \mathrm{L}$ \\
\hline Hemoglobin & $13.2 \mathrm{~g} / \mathrm{dL}$ & $12-16 \mathrm{~g} / \mathrm{dL}$ \\
\hline Platelet count & 245 cells $/ \mathrm{mcl}$ & $150-450$ cells $/ \mathrm{mcl}$ \\
\hline Erythrocyte sedimentation rate & $120 \mathrm{~mm} / \mathrm{h}$ & normal reference up to $20 \mathrm{~mm} / \mathrm{h}$ \\
\hline Serum urea & $24 \mathrm{mg} / \mathrm{dL}$ & $5-20 \mathrm{mg} / \mathrm{dL}$ \\
\hline Serum creatinine & $0.8 \mathrm{mg} / \mathrm{dL}$ & $0.5-1.1 \mathrm{mg} / \mathrm{dL}$ \\
\hline Serum Sodium & $137 \mathrm{mmol} / \mathrm{L}$ & $135-145 \mathrm{mmol} / \mathrm{L}$ \\
\hline Serum Potassium & $3.5 \mathrm{mmol} / \mathrm{L}$ & $3-3.5 \mathrm{mmol} / \mathrm{L}$ \\
\hline Serum albumin & $4.4 \mathrm{~g} / \mathrm{dL}$ & $2.4-4 \mathrm{~g} / \mathrm{dL}$ \\
\hline Serum globulin & $2.1 \mathrm{~g} / \mathrm{dL}$ & $2-3.5 \mathrm{~g} / \mathrm{dL}$ \\
\hline Total protein & $6.5 \mathrm{~g} / \mathrm{dL}$ & $6-8.3 \mathrm{~g} / \mathrm{dL}$ \\
\hline Total bilirubin & $0.56 \mathrm{mg} / \mathrm{dL}$ & $0.2-1.3 \mathrm{mg} / \mathrm{dL}$ \\
\hline Direct bilirubin & $0.23 \mathrm{mg} / \mathrm{dL}$ & $0.2-0.3 \mathrm{mg} / \mathrm{dL}$ \\
\hline Indirect bilirubin & $0.33 \mathrm{mg} / \mathrm{dL}$ & $0.2-0.3 \mathrm{mg} / \mathrm{dL}$ \\
\hline Alanine aminotransferase & $15 \mathrm{U} / \mathrm{L}$ & $10-130 \mathrm{U} / \mathrm{L}$ \\
\hline Aspartate aminotransferase & $43 \mathrm{U} / \mathrm{L}$ & $10-34 \mathrm{U} / \mathrm{L}$ \\
\hline Alkaline phosphatase & 65 U/L (24-147 UL) & 24-147 UL \\
\hline \multirow[t]{3}{*}{ Urine general } & ++++ Protein, oval fat deposition ++ & \\
\hline & $7-9$ pus & \\
\hline & Fatty cast ++ & \\
\hline 24 Urine proteins & 9.990 & 150 mg/day \\
\hline
\end{tabular}

he visited our hospital, he had massive ascites accompanied by renal and liver abnormalities. Because of the lack of evidence of an abdominal solid mass, we suspected that he had a recurrent abdominal $\mathrm{Tb}$, which can occur, especially in the highly endemic countries for Tb, such as Sudan. ${ }^{11}$ Unfortunately, we had no microbiological evidence for diagnosis of abdominal $\mathrm{Tb}$ due to techni-

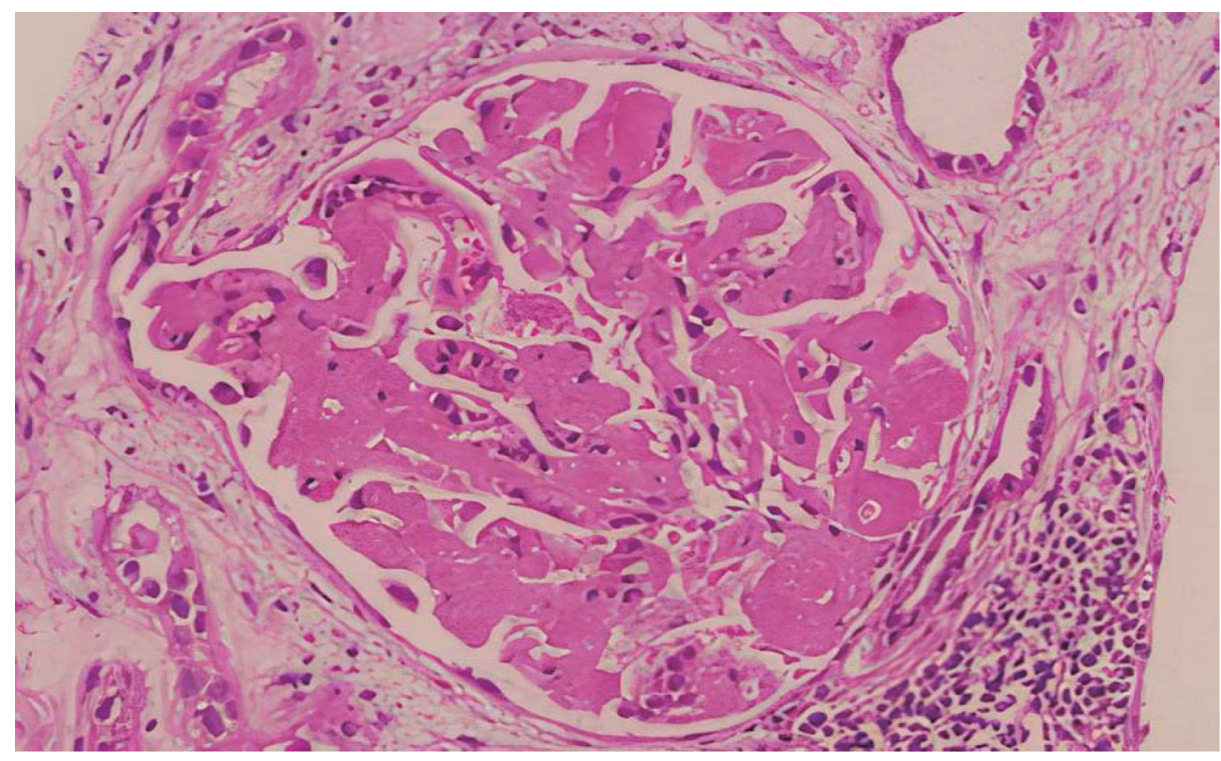

Fig. 2. Pathological findings of biopsied renal tissue. The section shows renal amyloidosis, wide mesangial increase by eosinophilic and noncellular material, extended to the loops of the glomerular capillary ( $\mathrm{H}$ and $\mathrm{E}$ stain, original magnification $\times 400)$. 
cal difficulty in our hospital. It is possible that this patient may have had a renal AL secondary to abdominal $\mathrm{Tb}$. Thus, physicians should pay special attention to those patients with abdominal $\mathrm{Tb}$ for potentially secondary AL, particularly in Tb epidemic regions.

$\mathrm{AL}$ is commonly diagnosed by histology and laboratory tests as well as by clinical symptoms, including evidence of apple-green birefringence in the affected tissues and findings from serum-free light chain assay. ${ }^{12,13}$ We did observe these pathological changes in renal biopsied tissues. Furthermore, our patient exhibited impaired heart function and we also detected abnormal echocardiograms. ${ }^{14}$ These findings, together with impaired renal function and systemic edema, prompted us to diagnose him with AL. Conceivably, consideration and performance of renal biopsy for histological examination are important for accurate diagnosis of renal AL.

Although therapeutic management of renal AL has been reported for many years, there is currently no specifically effective treatment for AL. Suppression of inflammation is the principle strategy for treatment of AL. This will decrease early phase reactants and lead to regression or stabilization of amyloid deposition. ${ }^{10}$ In addition, therapeutic treatment against interleukin- 1 and tumor necrosis factor-alpha have been tried in AL patients. ${ }^{15,16} \mathrm{~A}$ more anticipated approach to treatment of AL is the targeting of amyloid deposits. Treatments of renal AL to stabilize amyloid fibrils have been developed recently and have improved the prognosis for those patients..$^{17} \mathrm{We}$ treated our patient with a combination of several drugs to effectively ameliorate his clinical symptoms within 2 weeks. Therefore, combination of multiple arms of treatment to manage renal AL patient may be valuable for improving the prognosis of AL.

\section{Conclusion}

Renal AL is a rare disease that occurs due to deposition of amyloid in tissues and organs. Its diagnosis is usually difficult, due to its unspecific symptomology. We report a case of renal AL, demonstrated by renal tissue pathology. We found that combination of several drugs for treatment of renal AL effectively improved its clinical symptoms. Given that many secondary AL cases are neglected and missed for its diagnosis, this report should serve to alert clinicians to pay special attention to secondary AL while making differential diagnoses because of its potential for severe consequences without optimal treatment, particularly in high epidemic regions of $\mathrm{Tb}$, like Sudan.

\section{Acknowledgments}

The authors wish to acknowledge the support of Medical and Cancer research Institute (MCRI).

\section{Ethical statement}

The authors have obtained the written consent from the patient to publish this case report.

\section{Funding}

This study was funded by Medical and Cancer Research Institute (MCRI), Sudan.

\section{Conflict of interest}

The authors declare no competing interests.

\section{Author contributions}

ZIT is the supervisor rheumatologist who diagnose and manage the patient; follow-up, data collections and manuscript writing (MEAE, ATIA, MAEE, AAOE, SAAM), AAA contributed by critical revision of the study. All authors read and approved the final manuscript.

\section{References}

[1] Merlini G. AL amyloidosis: from molecular mechanisms to targeted therapies. Hematology Am Soc Hematol Educ Program 2017;2017(1):1-12. doi:10.1182/asheducation-2017.1.1.

[2] Bhuyan R, Tran TT, Mc Phaul L, Liu Y. Primary Amyloidosis. Am J Clin Pathol 2020;154(Supplement_1):S83-S8S. doi:10.1093/ajcp/ aqaa161.182.

[3] Sachchithanantham S, Offer M, Venner C, Mahmood SA, Foard D, Rannigan $\mathrm{L}$, et al. Clinical profile and treatment outcome of older (>75 years) patients with systemic AL amyloidosis. Haematologica 2015;100(11):1469-1476. doi:10.3324/haematol.2015.128025.

[4] Lane T, Pinney JH, Gilbertson JA, Hutt DF, Rowczenio DM, Mahmood $S$, et al. Changing epidemiology of AA amyloidosis: clinical observations over 25 years at a single national referral centre. Amyloid 2017;24(3):162-166. doi:10.1080/13506129.2017.1342235.

[5] Premkumar M, Rangegowda D, Vyas T, Kulkarni A, Grover S, Mahiwall $\mathrm{R}$, et al. Primary hepatic amyloidosis presenting as acute-on-chronic liver failure. ACG Case Rep J 2017;4:e22. doi:10.14309/crj.2017.22.

[6] Angel-Korman A, Stern L, Sarosiek S, Sloan JM, Doros G, Sanchorawala $\mathrm{V}$, et al. Long-term outcome of kidney transplantation in AL amyloidosis. Kidney Int 2019;95(2):405-411. doi:10.1016/j. kint.2018.09.021.

[7] Real de Asua D, Costa R, Galvan JM, Filigheddu MT, Trujillo D, Cadinanos J. Systemic AA amyloidosis: epidemiology, diagnosis, and management. Clin Epidemiol 2014;6:369-377. doi:10.2147/CLEP. S39981.

[8] Celtik A, Sen S, Keklik F, Saydam G, Asci G, Sarsik B, et al. A histopathological scoring and grading system to predict outcome for patients with AA amyloidosis. Int Urol Nephrol 2020;52(7):1297-1304. doi:10.1007/s11255-020-02505-y.

[9] de Asúa DR, Costa R, Contreras MM, Gutiérrez Á, Filigghedu MT Armas M. Clinical characteristics of patients with systemic amyloidosis from 2000-2010. Revista Clínica Española (English Edition) 2013;213(4):186-193. doi:10.1016/j.rceng.2012.09.001.

[10] Delplanque M, Galicier L, Oziol E, Ducharme-Bénard S, Oksenhendler $E$, Buob $D$, et al. AA amyloidosis secondary to primary immune deficiency: about 40 cases including 2 new French cases and a systematic literature review. J Allergy Clin Immunol Pract 2020. doi:10.1016/j. jaip.2020.09.023.

[11] Ruiz J, Ganji M, Canha C, Isache C. A Challenging Diagnosis of Ascites: A Case Report of Peritoneal Tuberculosis. Case Rep Infect Dis 2018;2018:8136476. doi:10.1155/2018/8136476.

[12] Yakupova EI, Bobyleva LG, Vikhlyantsev IM, Bobylev AG. Congo Red and amyloids: history and relationship. Biosci Rep 2019;39(1) BSR20181415. doi:10.1042/BSR20181415.

[13] Asahina A. Difficulty in confirming the diagnosis of bullous amyloidosis. Am J Dermatopathol 2014;36(5):446-447. doi:10.1097/ DAD.0b013e31828b2af0.

[14] Cavusoglu Y, Ozpelit E, Celik A, Ikitimur B, Kayikcioglu M, Tokgozoglu $L$, et al. Cardiac amyloidosis: Recent advances in the diagnosis and therapy. Turk Kardiyol Dern Ars 2019(Suppl 2):1-34. doi:10.5543/ tkda.2019.28035

[15] Özçakar ZB, Özdel S, Yılmaz S, Kurt-Şükür ED, Ekim M, Yalçınkaya F. 
Anti-IL-1 treatment in familial Mediterranean fever and related amyloidosis. Clin Rheumatol 2016;35(2):441-446. doi:10.1007/s10067014-2772-2.

[16] Courties A, Grateau G, Philippe P, Flipo R-M, Astudillo L, Aubry-Rozier $B$, et al. AA amyloidosis treated with tocilizumab: case series and up- dated literature review. Amyloid 2015;22(2):84-92. doi:10.3109/135 06129.2014.1002031.

[17] Ankarcrona M, Winblad B, Monteiro C, Fearns C, Powers ET, Johansson J, et al. Current and future treatment of amyloid diseases. J Intern Med 2016;280(2):177-202. doi:10.1111/joim.12506. 